\title{
Fabrication of Fe-Cr-Al Oxide Dispersion Strengthened PM2000 alloy using Selective Laser Melting**
}

By John Walker*, Kaj Berggreen, Andy Jones, Chris Sutcliffe

\author{
Dr J. C. Walker*, Mr K. M. Berggreen, Dr A. R. Jones, Dr C. J. Sutcliffe \\ University of Liverpool, Department of Engineering, Brownlow Hill, Liverpool, L69 3GH, \\ UK \\ *j.walker@soton.ac.uk
}

\section{** Acknowledgements}

The authors are grateful for funding from the Advanced Research Materials (ARM)

Programme, U.S. Department of Energy, Office of Fossil Energy.

\begin{abstract}
The expansion in application of the selective laser melting (SLM) process for fabrication of new alloy materials continues. However, to date, there has been no investigation of the effect of this process on the final microstructure of 'melt sensitive' powder alloys such as mechanically alloyed oxide dispersion strengthened (ODS) FeCrAl. In this study commercial PM2000 powder, a ferritic ODS alloy strengthened by a fine dispersion of nano-scale yttria particles, was used in a layer based SLM rapid prototyping process to manufacture thin walls. Laser input power and scan speeds were varied between $10-50 \mathrm{~W}$ and $0.1-0.3 \mathrm{~ms}^{-1}$, respectively. Electron channelling contrast images of the resulting microstructures revealed a columnar grain structure aligned perpendicular to the surface of the build substrate. Measurements of the diameter of yttria particles retained in the walls using transmission electron microscopy indicated that agglomeration and coarsening had taken place for samples processed at the slowest scan speed. By contrast ODS particles retained in a wall made at twice the slowest scan speed showed no evidence of agglomeration and appeared to have coarsened to a lesser extent, exhibiting a smaller mean diameter. This opens the possibility of using these alloys in novel applications processed using rapid prototyping technologies.
\end{abstract}

Keywords: Rapid prototyping (RP), selective laser melting (SLM), oxide dispersion strengthening (ODS), PM2000, electron microscopy.

\section{Introduction}

Ferritic oxide dispersion strengthened (ODS) alloys such as PM2000 offer a good combination of creep and oxidation resistance, especially at high operating temperatures 
$\left(>1000^{\circ} \mathrm{C}\right) .^{[1,2]}$ Such properties are achieved by the incorporation of elements such as aluminium and chromium which can form stable protective oxide barriers on the metal surface. The addition of a nano-scale, thermally stable dispersion of oxide particles based on yttria enhances the high temperature mechanical properties by impeding dislocation movement and encouraging a coarse grain structure on recrystallisation. ODS alloys are generally produced by mechanical alloying (MA) in order to achieve a fine distribution of oxide particles distributed throughout the matrix. ${ }^{[3]}$

Conventional processing techniques, which involve melting, tend to be avoided for these alloys, since oxide particles can coarsen significantly and slag off; factors which lead to loss of high temperature creep strength in the alloys. The joining of ODS alloys often represents the main obstacle to their widespread use in critical high temperature applications, although development of solid-state joining techniques such as friction stir-welding and plasma-assisted diffusion bonding ${ }^{[4]}$ have now gone some way to addressing these issues. Despite this, laser beam welding of a similar ODS alloy, MA956, has demonstrated that a yttria dispersion can be retained in the weld pool after solidification, although the mechanical properties of such joints tended to be inferior to the base alloy. ${ }^{[5]}$

More recently, the emergence of rapid prototyping (RP) layer based technologies such as selective laser sintering $(S L S)^{[6]}$ and selective laser melting $(S L M)^{[7,8]}$ have allowed the manufacture of solid near net-shape components from layered metallic powder beds. Whilst the field is progressing rapidly, a relatively narrow selection of alloys has been processed by SLM. Recent advances have included the characterisation of Ni-base superalloys ${ }^{[9]}$ produced by different SLM scanning strategies as well as the use of Ti and Co$\mathrm{Cr}$ for biocompatible medical parts. ${ }^{[10,11]}$ However, no cited references exist for the investigation of 'melt-sensitive' ODS alloys such as PM2000 by this process. The potential of processing such alloys using SLM is derived from the high solidification cooling rates typically associated with laser welding $\left(>10^{5 \circ} \mathrm{Cs}^{-1}\right)^{[12,13]}$ which suggests the possibility of the retention of the fine oxide dispersion in-spite of melting. ODS alloys are expensive due to the MA process and therefore a more direct and efficient use of PM2000 for producing certain components, with recovery of the un-used powder, is a further advantage of the SLM process compared to conventional techniques. PM2000 components manufactured by SLM may have potential for applications in high temperature furnaces, chemical reactors, as well as for orthopaedic uses. ${ }^{[12,14]}$

This investigation seeks to assess the suitability of PM2000 for rapid prototyping solutions using an SLM process by varying the laser power and scan speed for an optimum ODS dispersion. Scanning and transmission electron microscopy have been used to assess the microstructure of the as-manufactured PM2000 parts and the effect of processing parameters is discussed. 


\section{Experimental}

\subsection{Powder analysis and processing}

Commercially produced oxide dispersion strengthened alloy PM2000, of nominal composition indicated in Table 1, was supplied as powder by Plansee $\mathrm{GmbH}$, Austria, in the as-MA condition. A Hitachi S2460N scanning electron microscope (SEM) operating at 20kV was used to image the particle morphology, whilst a Malvern Instruments Mastersizer 2000 laser diffractometer allowed analysis of the particle size distribution. In order to prepare powder samples for particle size measurement, a small amount of powder was dispersed in de-ionized water with the aid of a non-ionic surfactant (Non-indet P40) and an ultrasonic probe. Five measurements were taken from two samples of powder and median values calculated.

\begin{tabular}{ccccc}
\hline $\mathrm{Cr}$ & $\mathrm{Al}$ & $\mathrm{Ti}$ & $\mathrm{Y}_{2} \mathrm{O}_{3}$ & $\mathrm{Fe}$ \\
\hline 19.0 & 5.5 & 0.5 & 0.5 & Balance \\
\hline
\end{tabular}

Table 1. Nominal composition (wt\%) of mechanically alloyed PM2000 alloy.

\subsection{Selective laser melting}

The majority of RP processes are layer-based additive methods which work by producing a structure as a stack of discrete layers, each corresponding to a slice of a CAD model. In SLM this is done by sequentially spreading a layer of metal powder and scanning the slice geometry onto the powder bed with a laser beam, melting and consolidating the powder only in these discrete areas. The substrate would be lowered to allow re-coating with a fresh powder layer and the process repeated, fusing selected areas to the previous slice. Thus intricate 3-dimensional metallic geometries which would be impossible to produce by conventional means can rapidly and effectively be custom manufactured. Un-fused powder is recycled upon completion and removal of the build from the process chamber.

The thickness of the powder layer influences the total build time and accuracy of a threedimensional part. It needs to be thin enough that the laser power is sufficient to fully melt the fresh powder layer and some of the underlying material in order to facilitate good bonding. However, it also has to be thicker than the maximum particle size used as feedstock, as previously solidified layers could be disturbed if a large particle was dragged across them during levelling of a new powder layer. ${ }^{[6]}$ When dropping the platform for a step height of $z$, the effective powder layer thickness, $d$, over a consolidated area converges towards $z$ / $a$ for more than 10 layers, with $a$ being the quotient of the apparent density of the as poured powder and the density of the solid material; referred to as the filling factor ${ }^{[15]}$. The apparent density was measured as $3.3 \mathrm{gcm}^{-3}$ while the density of PM2000, according to specification (Plansee), was $7.18 \mathrm{gcm}^{-3}$. This gave a filling factor of 0.46 resulting in an effective powder layer thickness of $108 \mu \mathrm{m}$ for a $50 \mu \mathrm{m}$ slice thickness in the consolidated 
product. Thus larger particles were removed from the as-received PM2000 powder using a 140 mesh $(106 \mu \mathrm{m})$ stainless steel sieve shaker. The particle size distributions of the sieved fractions were also measured with laser diffractometry using the same procedure as before.

In the current work, an SLM Realizer 100 machine (MTT Technologies, UK) was used to build thin walls onto a mild steel substrate. Single lines of $20 \mathrm{~mm}$ length were scanned into the powder bed by the laser. The substrate was lowered in the z-direction by $50 \mu \mathrm{m}$ followed by deposition of a new powder layer. The process was repeated until a z-height of $10 \mathrm{~mm}$ has been reached. The system uses an Ytterbium-doped fibre laser with a wavelength of 10701080nm (IPG Photonics) which was operated between 10-50W continuous wave, in 10W increments. A lens system focused the beam to $35 \mu \mathrm{m}$ diameter on the working plane at $50 \mathrm{~W}$ laser output power. Builds were completed at scan speeds selected between 0.1 to $0.3 \mathrm{~ms}^{-1}$ in increments of $0.05 \mathrm{~ms}^{-1}$. The build was carried out in a protective argon chamber operating at 15 mbar overpressure in order to keep the level of oxygen constant at $0.5 \pm 0.1 \%$. The build platform was preheated to $150^{\circ} \mathrm{C}$ to reduce thermal stresses. Two groups of identical walls were made on the substrate, each rotated $180^{\circ}$ from the other.

\subsection{Microstructural analysis}

Walls fabricated from PM2000 powders were removed from the mild steel substrate as close to the interface as possible. The microstructure of the walls was investigated using electron channelling contrast techniques in a Jeol 7001F field emission gun (FEG) SEM, operating at $10 \mathrm{kV}$. The channelling contrast technique allowed identification of grain structures and morphology through image contrast sensitive to local grain orientation. A number of walls were mounted either flat or end-on in conductive Bakelite resin and polished using conventional metallographic techniques to $1 \mu \mathrm{m}$ diamond and finished using a colloidal silica solution.

Representative samples from three walls $\left(20 \mathrm{~W}, 0.1 \mathrm{~ms}^{-1}, 50 \mathrm{~W}, 0.1 \mathrm{~ms}^{-1}\right.$ and $50 \mathrm{~W}, 0.2 \mathrm{~ms}^{-1}$ ) were also prepared for transmission electron microscopy (TEM) using an electro-polishing technique. $3 \mathrm{~mm}$ diameter foils were cut from each wall using a Gatan 601 ultrasonic disc cutter with 240 grit SiC water-based slurry. The discs were subsequently thinned at room temperature in a solution of $10 \%$ perchloric acid in 2-butoxyethanol, using a Streurs Tenupol-3 operating at 50V and $\sim 100 \mathrm{~mA}$. A Jeol 2000FX transmission electron microscope, operating at $200 \mathrm{kV}$, was used to image the microstructures in bright-field mode, whilst EDX analysis allowed further identification of elements present in areas of interest. Multiple bright field images were taken of different areas of the samples investigated in order to determine oxide particle size distributions. To correct for thin foil stereological factors, a correction based on the $\left(t_{f}+d\right)$ method proposed by Sellars and Smith was applied ${ }^{[16]}$. Measurement of foil thicknesses was estimated using extinction contours in weak beam $(\mathrm{g}, 3 \mathrm{~g})$ dark field images. ${ }^{[17,18]}$ 


\section{Results}

\subsection{Power particle size}
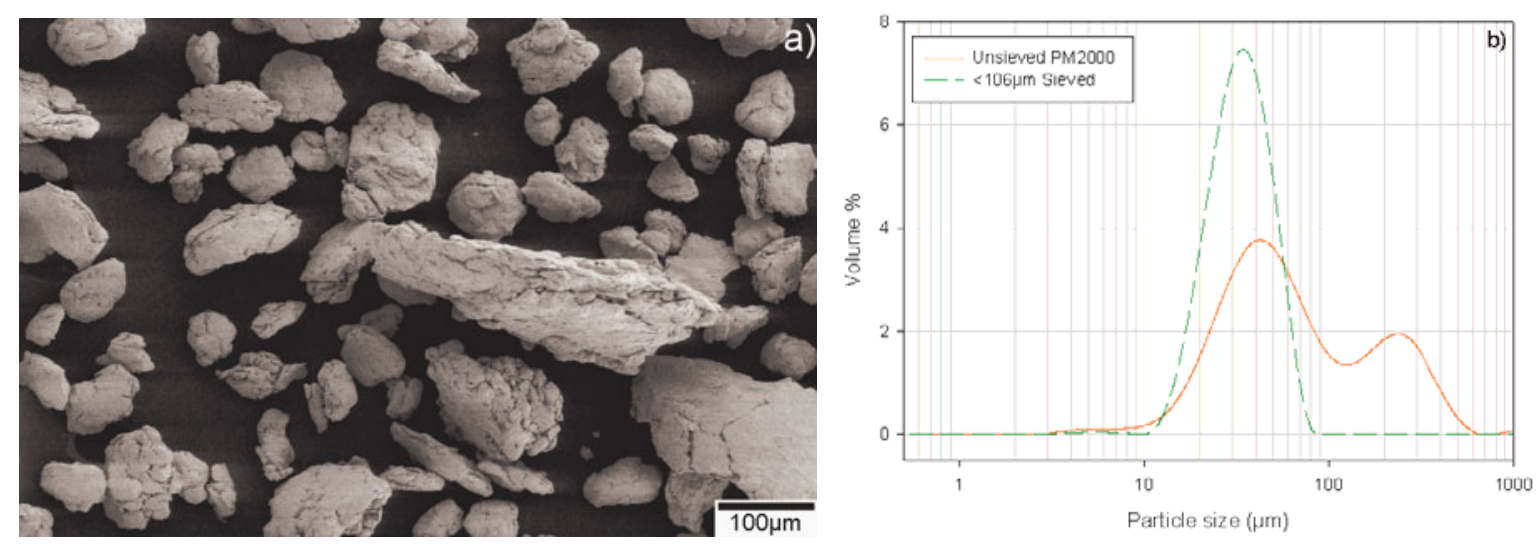

Fig. 1. (a) Scanning electron micrograph and (b) particle size distribution of the as-received PM2000 powder.

The as-received PM2000 powder, Figure 1a), exhibited a bi-modal particle size distribution, Figure $1 \mathrm{~b})$, with a median particle size $\left(d_{50}\right)$ of $47.2 \mu \mathrm{m}$ and peaks at $42.5 \mu \mathrm{m}$ and $218.7 \mu \mathrm{m}$. The smaller particles appeared to have a relatively equiaxed morphology, whilst the larger size fraction had a more plate-like aspect. Sieving with a $106 \mu \mathrm{m}$ mesh sieved separated the powder into a smaller size fraction with median particle size $\left(d_{50}\right)$ of $32 \mu \mathrm{m}$, and a residual, larger size fraction with a median particle size of $317 \mu \mathrm{m}$.
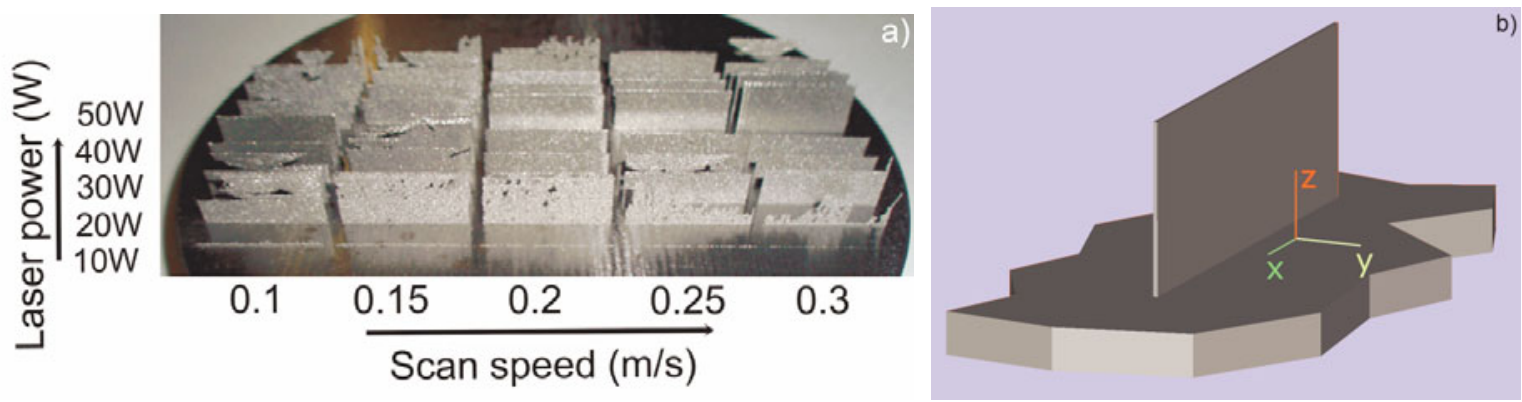

Fig. 2. (a) Image of PM2000 walls after recovery of loose powder from SLM process and (b) schematic of relative wall axis orientations.

\subsection{Microstructural analysis}

PM2000 SLM walls built using a laser power of 10W all crumbled when recovered from the build chamber, indicating that the bonding between the particles was insufficient for a solid build, Figure 2a). With a 20W laser power, only scan speeds of 0.1 and $0.15 \mathrm{~ms}^{-1}$ allowed construction of a wall of sufficient integrity to be removed from the substrate. Samples processed with 30, 40 and 50W laser powers all showed good integrity and adherence to 
the substrate across the range of scan speeds. The thickness of the walls, measured using callipers, was between $0.1-0.3 \mathrm{~mm}$, although there was no distinct trend in thickness associated with either the laser power or the scan speed. It appeared that the amount of melting and therefore the overall integrity of the walls increased with a slower scan speed or a higher laser power.

Electron channelling contrast images from polished flat and end sections of the walls revealed columnar grain structures, of the order of $100 \mu \mathrm{m}$ in length, elongated in the zdirection of the build (Figure 3a). Also evident was the significant difference in grain size between regions of the wall which had been melted and that in powder particles attached to the surface, in which grain size tended to be equiaxed and below $500 \mathrm{~nm}$. An example of an end wall transverse section through such a region $\left(50 \mathrm{~W}, 0.3 \mathrm{~ms}^{-1}\right.$ sample) is shown in the channelling contrast images presented in Figures $3 b-c)$. Nevertheless, this grain size was larger than the, generally, sub-100nm grain size of the as-MA PM2000 powder particles, shown in Figure 3d). Grains at the edge of the wall appeared inclined towards the wall centre, where larger, columnar grains were orientated parallel to the z-direction of the wall build. No evidence was found of un-melted powder particles being occluded within the centre of built walls. There was also very little apparent porosity.

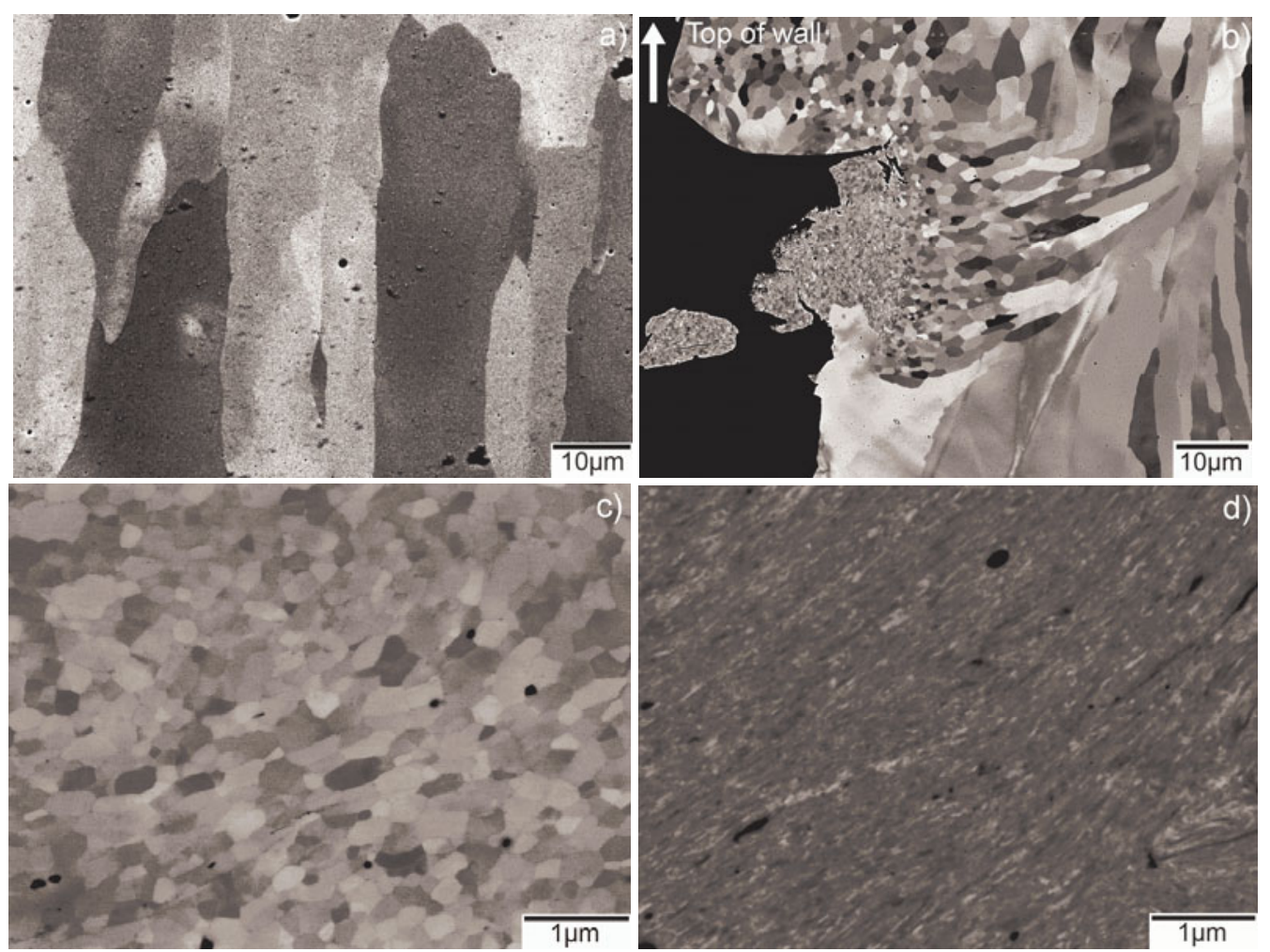

Fig. 3. Electron channelling contrast images of: (a) flat section of $50 \mathrm{~W}, 0.1 \mathrm{~ms}^{-1}$ wall viewed along $y$-axis; (b) end cross section viewed along $x$-axis (c) surface powder particle from $50 \mathrm{~W}$, $0.3 \mathrm{~ms}^{-1}$ wall viewed along $\mathrm{x}$-axis and (d) Mechanically Alloyed PM2000 particle. 


\subsection{Analysis of oxide particle size distributions}

Transmission electron microscopy allowed detailed imaging of the microstructure in the PM2000 SLM walls at the nano-scale. The columnar grain structure, already observed in the electron channelling contrast images (Figure 3), was clearly evident in Figure 4a). TEM images also revealed that dispersions of oxide particles were retained in the built walls, Figures 4 and 5 . However, the relative size distribution varied according to individual build parameters. Amongst the samples examined, the $50 \mathrm{~W}, 0.2 \mathrm{~ms}^{-1}$ wall exhibited the distribution of oxide particles showing least evidence of particle coarsening and agglomeration, Figure 4. Whilst such regions of homogeneous oxide distribution were also evident in the $50 \mathrm{~W}$ and $20 \mathrm{~W}$ samples processed at $0.1 \mathrm{~ms}^{-1}$ scan speed, Figures $5 \mathrm{~b}$ ) \& d), a notable difference was the presence of regions where significant particle agglomeration appeared to have occurred, Figures $5 a$ ) and $5 c$ ). The mean oxide particle diameter in the $20 \mathrm{~W}$ and $50 \mathrm{~W}, 0.1 \mathrm{~ms}^{-1}$ samples, corrected for the stereological effects of foil thickness, was $53.9 \pm 17.4 \mathrm{~nm}$ and $60.7 \pm 22.9 \mathrm{~nm}$, respectively, Figure 6 . The mean particle diameter in the $50 \mathrm{~W}, 0.2 \mathrm{~ms}^{-1}$ wall was $48.4 \pm 25.2 \mathrm{~nm}$, which was slightly lower than the mean particle diameter in walls built at $0.1 \mathrm{~ms}^{-1}$, but still larger than the $30.0 \pm 8.9 \mathrm{~nm}$ mean diameter of ODS particles found in PM2000 alloy subject to conventional solid state consolidation, processing and recrystallisation annealing $\left(60\right.$ minutes at $\left.1380^{\circ} \mathrm{C}\right)$.
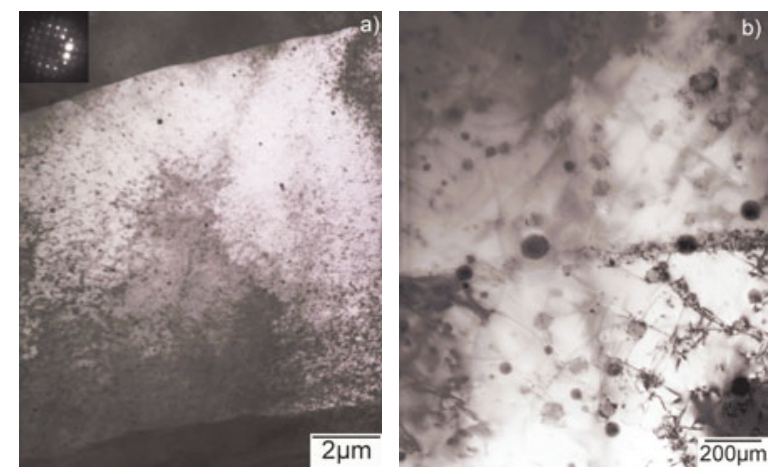

Fig. 4. Bright field TEM images from a section of the $50 \mathrm{~W}, 0.2 \mathrm{~ms}^{-1}$ wall viewed along the $\mathrm{y}$ axis of the wall.

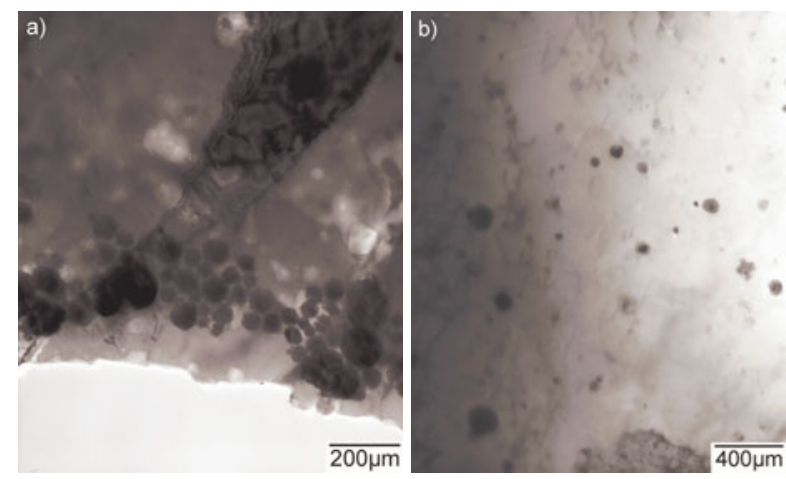




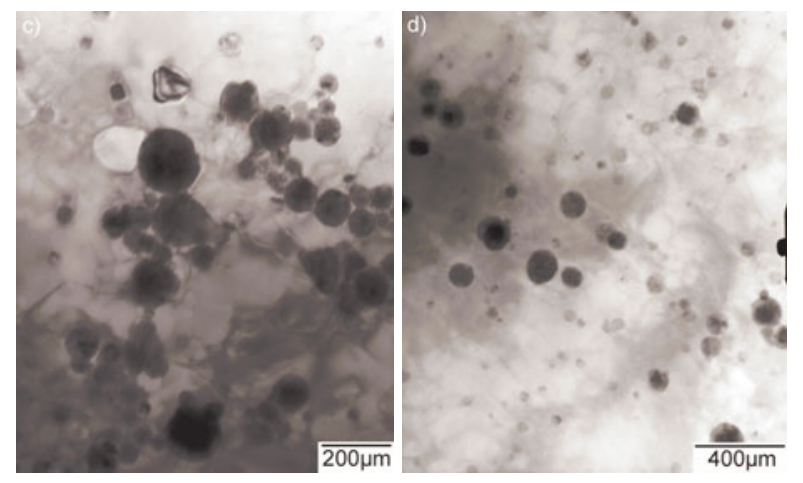

Fig. 5. Bright field TEM images from sections of (a-b) 50W, $0.1 \mathrm{~ms}^{-1}$ and (c-d) $20 \mathrm{~W}, 0.1 \mathrm{~ms}^{-1}$ walls, viewed along the $y$-axis.

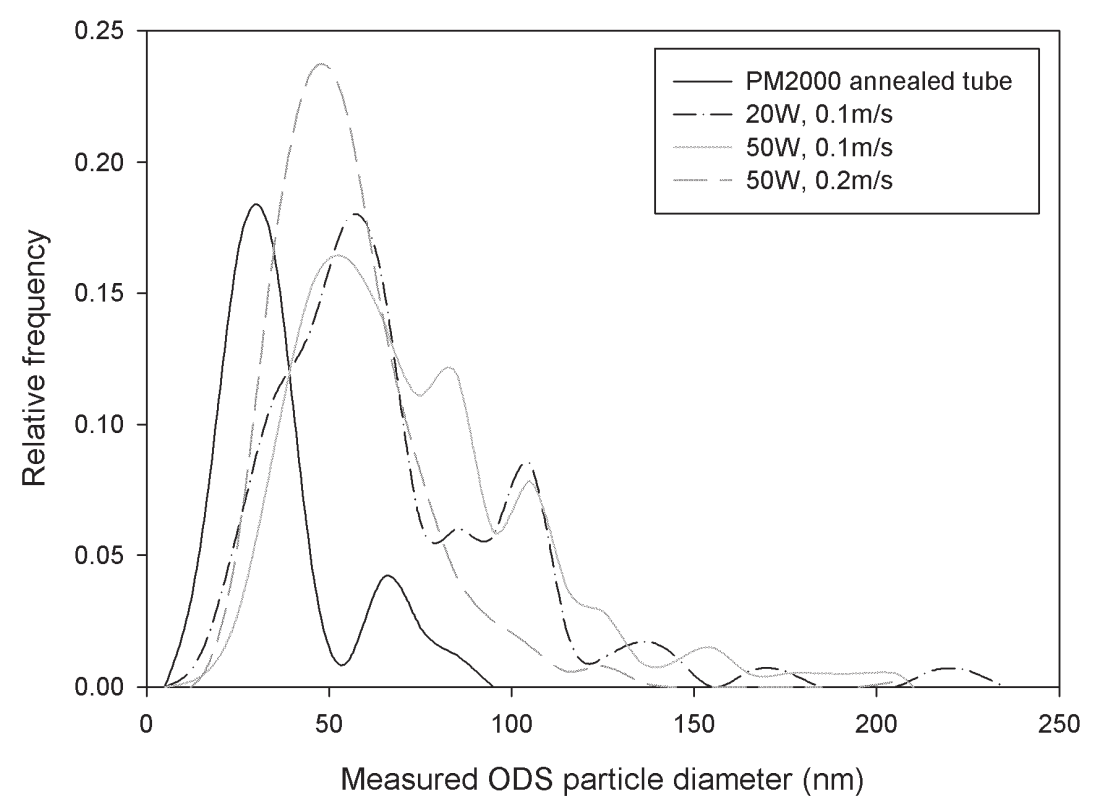

Fig. 6. ODS particle size distribution in PM2000 SLM walls, compared to a conventionally processed $\mathrm{PM} 2000$ tube, annealed at $1380^{\circ} \mathrm{C}$ for 60 minutes.

\section{Discussion}

The as-received PM2000 powder exhibited a bi-modal particle size distribution with larger particles having a plate-like morphology. Initial grain sizes of $100 \mathrm{~nm}$ in diameter or below, together with the heavily deformed, folded microstructure in these powders, Figure $3 \mathrm{~d}$ ), reflect the high impact energies developed during the MA process. ${ }^{[3]}$ Overall, particularly in terms of powder flow behaviour, the suitability of the $<106 \mu \mathrm{m}$ sieved PM2000 powder fraction for the SLM process has been clearly demonstrated by the successful building of layered single laser beam walls.

The thermal energy supplied by a $10 \mathrm{~W}$ laser beam was found to be insufficient to consolidate PM2000 powder particles in a wall that retained any useful strength. Doubling 
the laser power produced walls of sufficient integrity to be investigated, but only at scan speeds below $0.2 \mathrm{~ms}^{-1}$; results which are consistent with the literature in other investigations of metallic powder processing using the SLM process. ${ }^{[8,19,20]}$

The columnar grain structures observed in the electron channelling contrast and bright field transmission electron microscope images are evidence that complete melting of the PM2000 alloy had taken place, resulting in high density walls. Columnar rather than equiaxed microstructures are often formed as the result of laser melting where high scan speeds and small laser spot sizes are used, resulting in rapid cooling rates. ${ }^{[21,22]}$ Sharp changes in grain direction observed near the centre of the $50 \mathrm{~W}, 0.3 \mathrm{~ms}^{-1}$ wall (Figure $3 \mathrm{~b}$ ), were where grain growth inclined from the outer part of the wall appeared to change direction and align with the vertical columnar structure. Again, this change in grain morphology was believed to be the result of thermal gradients, these being higher at the centre of the wall, where most of the heat imparted by the laser was conducted towards the substrate. There was also a significant transition in grain size between powder particles attached to the outer surface of the wall and the bulk of the wall itself. Channelling contrast images, Figures $3 c$ ) and d), revealed that whilst the grain size in these particles was small $(<500 \mathrm{~nm})$ there had been some coarsening compared to the grain size in the as-received MA powders $(<100 \mathrm{~nm})$. Thus, while the outer particles may have remained partially unincorporated and un-melted during the SLM process, the high level of deformation imparted by the original MA process made the grain structure sensitive to the annealing cycle during SLM.

Melting of ODS alloys, particularly that characteristic of conventional joining techniques, is generally found to be detrimental to their high temperature mechanical properties, as the homogeneous oxide dispersion tends to be removed from the microstructure and slag off to the surface of the melt. ${ }^{[3]}$ In the present study there is strong evidence that a significant proportion of the oxide particle distribution can be retained within the PM2000 SLM walls, consistent with the suggestion of earlier work on laser joining of similar ODS materials. ${ }^{[5]}$

Whilst TEM of the $20 \mathrm{~W}$ and $50 \mathrm{~W}$ walls built at a laser scan speed of $0.1 \mathrm{~ms}^{-1}$ showed evidence of regions with a relatively even distribution of oxide particles, there were other areas within the same sample which appeared to exhibit distinct agglomeration of ODS particles, Figure 5a) and c). This was interesting, as it was initially thought that a laser power as low as $20 \mathrm{~W}$ might reduce such effects. In contrast, the $50 \mathrm{~W}$ wall produced at the faster scan speed of $0.2 \mathrm{~ms}^{-1}$ exhibited no agglomeration and a homogeneous distribution of oxide particles in the columnar grain structure. It is believed that this is the result of the rapidly resolidification of the melt pool behind the laser spot, ${ }^{[23]}$ thus reducing the effects of melt flow due to surface tension driven Marangoni convective stirring. ${ }^{[24]}$

The influence of laser scan speed on oxide coarsening was revealed in the oxide particle size distributions measured after SLM consolidation of the powders. Typical oxide particle

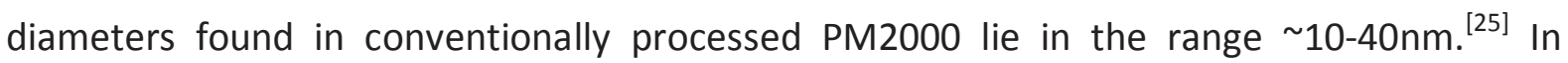


contrast, the average size of oxide particles after consolidation of the PM2000 powder at a laser scan speed of $0.1 \mathrm{~ms}^{-1}$ ranged between $54-61 \mathrm{~nm}$, indicating that the oxide had undergone some coarsening. High temperature coarsening of yttria-alumina oxides in ODS alloys has been shown to have a detrimental effect on the mechanical properties of the material, ${ }^{[26]}$ contributing, for example, to the poor mechanical properties found in laser welded MA956 ${ }^{[5]}$ and PM1000 joints. ${ }^{[27]}$ However, in the SLM wall processed at a laser scan speed of $0.2 \mathrm{~ms}^{-1}$, the average oxide particle diameter was $48 \mathrm{~nm}$; smaller than in the walls built at slower scan speed, but still somewhat larger than the mean particle diameters observed in a conventionally processed and annealed PM2000 component. Thus it appears that for this class of alloy which is sensitive to melting, the dwell time rather than the power of the laser may have more influence over the final oxide particle size distribution and, therefore, likely final properties. Such findings are consistent with numerical modelling of laser generated melt puddles, where cooling rates at solidification temperatures have been shown to increase with an increase in scanning speed. ${ }^{[12,13]}$

Optimisation of the SLM processing parameters may, therefore, open a new window of opportunity for fabricating components in such materials where high temperature properties can be retained in a dispersion strengthened microstructure. Potential applications of SLM built PM2000 parts include custom made orthopaedic hip joints, high temperature heat exchanger and chemical tubing as well as conventional furnace furniture components. Work is currently underway to establish optimised process conditions for the manufacture of three dimensional parts from PM2000, with a view to assessing the mechanical properties required for end-user applications.

\section{Conclusions}

- The suitability of commercial mechanically alloyed PM2000 alloy powder for rapid prototyping using the selective laser melting process has been demonstrated by the successful manufacture of single beam thickness consolidated walls.

- Due to the high amount of stored energy in the MA PM2000 powder particles, particles attached to the surface of built walls were often annealed, exhibiting a larger equiaxed grain size than in powder in the as-MA condition. The local grain size and aspect ratio increased with distance towards the centre of the SLM wall.

- A relatively fine distribution of oxide particles was retained in the built SLM walls in all samples investigated suggesting this technique may find application for building components in such melt sensitive alloys.

- The coarsening and agglomeration of fine oxide particles appeared to be influenced more by laser scanning speed than laser power.

\section{References}


[1]H. Al-Badairy, G. J. Tatlock, Mater. High Temp. 2000, 17, 133.

[2]A. Wasilkowska, M. Bartsch, U. Messerschmidt, R. Herzog, A. Czyrska-Filemonowicz, J. Mater. Process. Technol. 2003, 133, 218.

[3]C. Suryanarayana, Prog. Mater. Sci. 2001, 46, 1.

[4]G. J. Tatlock, E. G. Dyadko, S. N. Dryepondt, I. G. Wright, Metall. Mater. Trans. A 2007, 38A, 1663.

[5]T. J. Kelly, Highway Engineer 1979, 43.

[6]M. Agarwala, D. Bourell, J. Beaman, H. Marcus, J. Barlow, Rapid Prototyping J. 1995, 1, 26.

[7]J. P. Kruth, G. Levy, F. Klocke, T. H. C. Childs, CIRP Annals - Manufacturing Technology 2007, 56, 730.

[8]E. C. Santos, K. Osakada, M. Shiomi, Y. Kitamura, F. Abe, Proc. Inst. Mech. Eng. C, J.Mech. Eng. Sci. 2004, 218, 711.

[9]K. A. Mumtaz, P. Erasenthiran, N. Hopkinson, J. Mater. Process. Technol. 2008, 195, 77.

[10]B. Vandenbroucke, J. Kruth, Rapid Prototyping J. 2007, 13, 196.

[11]P. Fox, S. Pogson, C. Sutcliffe, E. Jones, Surf. Coat. Technol. 2008, 202, 5001.

[12]T. Chande, J. Mazumder, J. Appl. Phys. 1984, 56, 1981.

[13]T. Zacharia, S. A. David, J. M. Vitek, T. Debroy, Metall. Trans. A 1989, 20, 957.

[14]G. Strehl, J. L. Gonzalez-Carrasco, J. L. Peris, M. A. Montealegre, S. Garcia, C. Atienza, G.

Borchardt, Surf. Coat. Technol. 2006, 201, 148.

[15]W. Meiners, Direktes Selektives Laser Sintern einkomponentiger metallischer Werkstoffe, Thesis, RWTH Aachen, 1999.

[16]C. M. Sellars, A. F. Smith, J. Mater. Sci. 1967, 2, 521.

[17]P. K. Madden, V. M. Callen, J. Mater. Sci. 1983, 18, 3363.

[18]P. B. Hirsch, A. Howic, R. B. Nicholson, D. W. Pashley, M. J. Whelan, Electron Microscopy of Thin Crystals, Vol. 1965, Butterworths, London 1965.

[19]A. V. Gusarov, I. Yadroitsev, P. Bertrand, I. Smurov, Appl. Surf. Sci. 2007, 254, 975.

[20]R. Morgan, C. J. Sutcliffe, W. O'Neill, Rapid Prototyping J. 2001, 7, 159.

[21]W. Kurz, C. Bezencon, M. Gaumann, Sci. Technol. Adv. Mater. 2001, 2, 185.

[22]B. Zheng, Y. Zhou, J. E. Smugeresky, J. M. Schoenung, E. J. Lavernia, Metall. Mater. Trans. A 2008, $39 A, 2228$.

[23]J. P. Kruth, L. Froyen, J. Van Vaerenbergh, P. Mercelis, M. Rombouts, B. Lauwers, J. Mater.

Process. Technol. 2004, 149, 616.

[24]J. M. Drezet, S. Mokadem, Solidification and Gravity IV 2006, 508, 257.

[25]M. Klimiankou, R. Lindau, A. Moslang, J. Schroder, Powder Metall. 2005, 48, 277.

[26]C. G. Oca, M. A. Munoz-Morris, D. G. Morris, Intermetallics 2003, 11, 425.

[27]H. J. K. Lemmen, K. J. Sudmeijer, I. M. Richardson, S. van der Zwaag, J. Mater. Sci. 2007, 42, 5286. 


\title{
Fabrication of Fe-Cr-Al Oxide Dispersion Strengthened PM2000 alloy using Selective Laser Melting
}

\author{
J. C. Walker*, K. M. Berggreen, A. R. Jones, C. J. Sutcliffe
}

Rapid prototyping using the selective laser melting process has been successfully used in the manufacture of solid walls from melt sensitive mechanically alloyed PM2000 FeCrAl ODS powder. Despite melting of the powder, the technique allowed the retention of the nano-scale oxide dispersion due to the high cooling rates. Results showed that coarsening and agglomeration of ODS particles was more dependent on the laser dwell time rather than the maximum laser power.

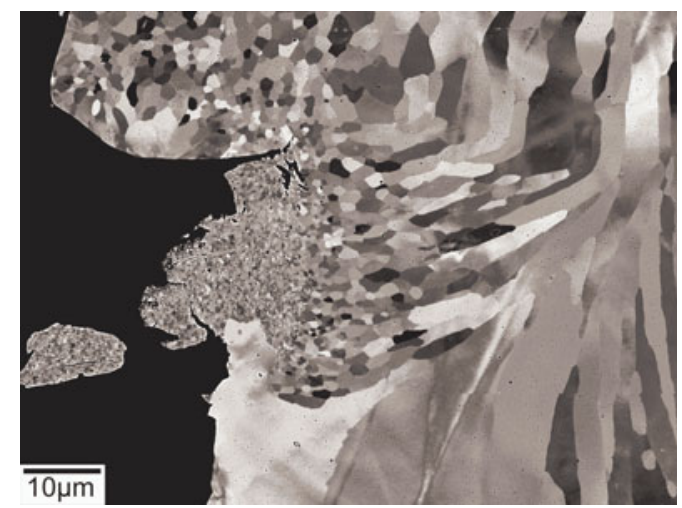

